\title{
The Function of Dieticians and their Role in the Future
}

Miss M. C. Broatch (King Edward's Hospital Fund for London,

10 Old Jewry, London, E.C.2)

It is difficult to separate the subject of the training of dieticians from that of their function and, therefore, if I repeat some of what has already been said, I hope $I$ shall be forgiven.

\section{The Meaning of the Term "Dietician"}

Before speaking about the function of a dietician I want to do two things. First, I want to make it quite clear that when speaking of a dietician $I$ have in mind a person who combines a sound scientific knowledge of nutrition with a practical knowledge of cooking, who can interpret standard requirements not only in calculations on paper but in such a practical way that the food will reach the consumer in palatable form and can be consumed with pleasure.

Second, I want to give a brief history of dieticians in this country because only by so doing can it be explained why to many people the term dietician has come to mean someone whose work is connected with hospitals and with hospitals only.

\section{History of Dietetics in this Country}

Dietetics in this country is a young profession. The first dieticians were appointed to meet the demand of the medical profession for someone who could arrange special diets for patients who were suffering from diseases in the treatment of which diet is an important factor. In this we were a long way behind the United States of America, and Canada, where the need for such people was realized during the war of 1914-18. By 1925, when the matter was being given consideration in this country, the profession was well established in both the U.S.A. and Canada where dieticians had formed themselves into a strong and powerful body, the American Dietetic Association, and special training was given in many of the universities and hospitals. I think I can illustrate this best by the fact that, when I attended the annual conference of the American Dietetic Association in Toronto in 1930, there was some disappointment at what was called the smallness of the attendance; there were about 2000 people there, whereas one other dietician from England and myself represented 50 per cent. of the dieticians in England.

The first dieticians to be appointed in the United Kingdom had to go to the U.S.A. to train, and I think I am right in saying the first to go was Miss Simmonds from the London Hospital in 1925. She was followed later by Miss Pybus from Edinburgh, and still later by Miss Abrahams from St. Bartholomew's, myself from St. Thomas's and Miss Marshall from University College Hospital. The training was primarily to fit us for taking charge of special diet kitchens in our respective hospitals. We were, however, fortunate in that we were able to work with dieticians in America who had far outgrown special diet kitchens and were in charge of the whole of the catering in many of the larger hospitals. Some of us were especially privileged in being able to study under Professor Sherman or Professor Mary Swartz Rose.

voc. 4,1946$]$ 
Special diet kitchens were opened in all the hospitals I have mentioned; three of the dieticians in these hospitals were trained nurses and two were what has come to be known as non-nurse dieticians. There was a good deal of controversy in the hospitals because it was felt by many matrons that dieticians should be trained in nursing. If I may be allowed to be personal for a moment, I would like to say that more by good luck than good management I first took the three year course in household and social science at King's College for Women; I followed it with a nurse's training and nursed for several years before studying dietetics in America. While my nurse's training has been most helpful in making me realize the peculiar difficulties of hospitals, I do not think it is a necessary part of the training of a dietician, nor does it in any way justify the demand that others should take the prolonged training which it entails.

\section{The Need for Training in this Country}

It soon became obvious that, as other hospitals wished to open special diet departments, some training must be established in this country. Two of the hospitals in London opened their doors to students who held degrees in domestic subjects or pure science, or diplomas in domestic science with an additional training in cookery, and offered to them a six months' training in the special diet kitchens. This again was soon found to be inadequate and in 1933 King's College started a postgraduate diploma course in dietetics which included theoretical work and six months' practical work in a special diet department. A similar course was opened at the Glasgow and West of Scotland College of Domestic Science, and Miss Pybus established a school of dietetics in Edinburgh which, though open only to nurses at first, later opened its doors to other students with suitable qualifications.

\section{Work of Dieticians \\ Function of Dieticians in the Special Diet Kitchen}

The function of dieticians in charge of special diet kitchens is to provide diets prescribed for patients by the physician or surgeon. They must, therefore, be able to calculate and prepare a diet containing given quantities of nutrients. It is easy to calculate a diet on paper, but quite a different matter and much more difficult to calculate a diet to a preseribed figure for a specific patient when his appetite, likes and dislikes also must be considered, nor does the dietician's work end there. She must be able to cook the meal in an appetizing form and serve it attractively to the patient. It is obviously absurd to spend time in an office calculating the composition of a diet if, when the food reaches the patient, it is not eaten and goes into the pig pail. Patients who require a special diet may be in-patients or out-patients. If the former, they have usually to continue their diet when they go home; the dietician must, therefore, be able to fit the diet to the physician's orders and to the patient's home conditions. She must produce diets at varying costs and arrange them so that they can be taken when patients are working; this quite often entails making the meals suitable for different shifts of work.

\section{Training of Students in the Special Diet Kitchen}

There is a good deal of eriticism of the training of dieticians because it requires students to spend a certain time in a special diet kitchen. 
Personally I think this training is invaluable; the student becomes familiar with the nutrient value of different foods and learns to appreciate the size of portions and the importance of individual likes and dislikes. During this training she receives constant teaching by a qualified dietician, which it would be difficult to give in kitchens catering for larger numbers. Work in canteens and in large kitchens is heavy work and the people in charge have little time for individual instruction and, while such training in large scale catering is essential, I do not think it can entirely replace that of the special diet kitchen but should rather follow it.

\section{General Work of Dieticians}

Most of the first dieticians who took this training went on to posts in special diet kitchens in hospitals. The field was, however, widening. A dietician had been appointed to the post of organizer of school meals in the London County Council; the Ministry of Health was employing dieticians in survey work, and some of the public schools had appointed dieticians in charge of their catering, but it is not difficult to see why dieticians were associated in people's minds more with hospital work than with any other. This was the position at the beginning of the war. The number of dieticians holding posts as organizers of school meals had increased, as also had those doing survey work, but the majority were still in hospitals.

At the beginning of the war the profession suffered a setback; hospitals, especially in London, were dispersed and many of the departments were closed down. In some instances dieticians were drafted into sector hospitals, but were not recognized as such; some indeed lost their status and were classified as cooks. Facilities for training were consequently reduced, new students were discouraged and newly qualified dieticians tended to drift into other spheres of national service. Recovery began after 1942; departments re-opened in hospitals, the Ministry of Food appointed dieticians in the Food Advice Division, and others found catering posts in the Services, but there had been a period of two years during which the number of students training had fallen considerably.

In 1943-44 there was a very marked increase in the demand for dieticians, and this demand has continued and now far exceeds the supply. The reasons for this were that local authorities began to provide school meals on a more extensive scale and appointed dieticians as organizers of school meals, and there was also a marked increase in the demand for dieticians in hospitals. This followed the publication of a memorandum on hospital diet published by King Edward's Hospital Fund for London (1943), and a memorandum published by the Ministry of Health (1945). Both the Fund and the Ministry appointed dieticians to form dietetic advisory services. Hospitals wish to appoint dieticians in full charge of their catering; this involves a knowledge of special diets and of large scale catering and, owing to the set-back in the first years of the war, there have not been the opportunities for dieticians to acquire this experience. The 'end of the war has brought a demand also for dieticians for work overseas, and by drawing on the supply for this purpose we find ourselves in still greater difficulties in this country.

Another new and important field of work has been opened in the appointment of dieticians in an advisory capacity to local authorities. voL. 4,1946 ] 
The health of the people is to a large extent the responsibility of the medical officer and, as nutrition is an important factor in maintaining health, it seems natural that an expert on this subject should be appointed to the staff of the local authority to advise on all matters of feeding. This includes foeding in hospitals, institutions, welfare centres and, to some extent, schools. In many institutions the catering is in the hands of people with little or no knowledge of nutrition, and the cooks are untrained and have often had no experience outside the kitchen in which they are working. It is not surprising, therefore, that the standard of feeding is not always what it should be. If this standard is to be improved, the feeding must be put into the hands of someone who combines a knowledge of nutrition with a practical knowledge of cooking and kitchen management. I cannot stress too strongly that, if dieticians are to hold posts where they are to give advice or be responsible for catering in any form, they must have, in addition to a sound theoretical training, a real knowledge and understanding of cooking, kitchen equipment and management.

There is a very wide field open to dieticians as regards their function in the future, not only in hospitals, schools and industrial canteens, but also in connexion with the new health services, in welfare centres, in prenatal and post-natal clinics and in education.

I have recently seen the report of a nutrition conference held in Canada. The programme of work outlined includes work similar to that which I have mentioned, with this difference, that dieticians in Canada are already well established in the health services. The posts they hold in addition to those which I have mentioned include ones in educational work; this consists of imparting nutritional knowledge directly or assisting in broad programmes of education intended to reach large sections of the public.

Time does not permit me to give in detail the functions involved in these various branches of work, nor is it necessary for me to do so since others will speak of the function of dieticians and the need for them in the different fields of work now open to them.

REFERENCES

King Edward's Hospital Fund for London (1943). Memorandum on Hospital Diet. London: Geo. Barber and Son, Ltd.

Ministry of Health (1945). Circ. Minist. Hlth, no. 44-45.

\title{
The Function of Dieticians and their Role in the Future with Special Reference to the United States and Canada
}

\author{
Mr. A. N. Childs (Empire Tea Bureau, 22 Regent Street, London, S.W.1)
}

In the United States the course of training offered to dieticians places them generally in two categories, those in hospitals and institutions, and those in commerce generally.

\section{The Hospital Dietician}

Although, prior to the war, I had many years of close association with the dieticians in commerce, of which I will speak later, as Catering 